\title{
Efficacy of Quichua healers as psychiatric diagnosticians
}

\author{
Mario Incayawar
}

\begin{abstract}
Summary
Traditional healers' practices are widespread around the world, yet their diagnostic skills have rarely been investigated. This exploratory study examines whether yachactaitas (Quichua healers) in the Andes identify cases of psychiatric illness in their communities. For over 18 months, ten yachactaitas participated in the identification of 50 individuals with the condition known as Ilaqui. Medical and psychiatric evaluation indicated that most of those so diagnosed had a DSM-III-R mental disorder. None of the
\end{abstract}

participants with Ilaqui was considered healthy in biomedical or psychiatric terms. It is suggested that yachactaitas might indeed identify general psychiatric cases in their communities, and that this might be useful for screening purposes

\section{Declaration of interest}

None. Funding detailed in Acknowledgements.
Traditional healers have attracted the attention of scholars for many years. ${ }^{1}$ Typically the research on this subject covers many topics, ranging from the social, religious and political roles of healers to the study of their mental status, doctor-healer collaboration, treatment efficacy and the characteristics of those who seek healers' services. ${ }^{2-4}$ In the Americas, indigenous healers and their healing methods have been studied extensively. ${ }^{5-7}$ However, little is known about the diagnostic strategies used by traditional healers in general, and even less is known about those used by healers in the Andes. Our knowledge is particularly limited on issues related to, for example, how healers make a diagnosis, their diagnostic criteria and their reliability as diagnosticians. This paper explores whether yachactaitas, the Quichua healers of the Andes, do in some way identify those in the community who are psychiatrically ill.

\section{Method}

This exploratory, case-series descriptive study was conducted in Otavalo, in the province of Imbabura in the highlands of Ecuador. Ten participating healers from three rural Quichua villages drew patients from the surrounding areas. The convenience sample of 50 participants with the condition known as llaqui were identified and selected by yachactaitas during a period of 18 months. For this study we were not able to have a control group. After complete description of the study to the participants, culturally appropriate family-based and community-based informed consent was obtained. The 50 participants were referred to a Quichua-speaking physician trained in transcultural psychiatry. All of these participants underwent the following investigations:

(a) a structured interview, using a Quichua questionnaire on the nature of llaqui;

(b) a medical evaluation, including personal and medical history, and physical examination;

(c) laboratory tests, including blood, faecal and urine analysis, and an $\mathrm{x}$-ray;

(d) psychiatric evaluation and diagnosis using DSM-III-R criteria ${ }^{8}$

(e) an adapted Quichua version of the Zung Self-Rating Depression Scale. ${ }^{9}$
Both the questionnaire on the nature of llaqui and the Zung depression scale were pre-tested with 10 volunteers, in order to check questions for clarity and accuracy. The Zung scale was read to the participants because many of them were illiterate. Our categorical data were analysed using basic descriptive statistics.

\section{Results}

The majority (94\%) of our participants reported living in the rural villages of the Otavalo area. Most of them were peasant farmers, artisans or homemakers. More than half $(56 \%)$ were illiterate and an additional $34 \%$ had not completed elementary school education. The sample was $54 \%$ male and $46 \%$ female; $65 \%$ were married.

\section{Quichua diagnosis}

The Quichuas themselves - and yachactaitas in particular identify llaqui as a cluster of four illness sub-categories, namely mancharishca, wairashca, shungu nanay and rurashca. Llaqui is a complex category comprising a symptom (sadness), the name of an illness, life events and a causal factor of illness. It is worth noting the low importance of symptom configuration as a criteria for defining llaqui and its sub-categories among the Quichuas. Rather, causal factors play a more important part in defining illness categories. For brevity, the two first sub-categories are merged into one, which can be translated as 'victim of malignant spirits'. According to the Quichuas, mancharishca or wairashca is a condition resulting from a sudden fright and approaching 'bad places'. The person is under attack by natural spirits or spirits under human control that will damage the person's body or soul. From the Quichuas' point of view, people with mancharishca or wairashca present a wide variety of unrelated physical and psychological symptoms. In biomedical terms, the condition resembles infectious disease or certain organic conditions. The third sub-category, shungu nanay (heart pain or shattered heart), results from life events and sorcery. Among the Quichuas, land disputes, family conflicts and the death of a relative are the most stressful life events. Despite the usual dismissal of symptom patterns, the Quichuas consider epigastric pain and convulsionlike episodes as key symptoms of shungu nanay; this condition also resembles the symptoms typical of anxiety and depression. The fourth sub-category, rurashca (victim of sorcery), is believed 
to result from the aggression of malignant spirits under human control (usually a healer) or by a physical or visual contact with materials used in the treatment of sorcery, including plants, food, animals and clothes. Comorbidity is not rare; people can have symptoms from more than one illness category simultaneously.

\section{Western clinical diagnosis}

The medical, psychiatric and psychometric evaluations of the 50 participants with llaqui revealed the high frequency of depressive disorders and of parasitic and infectious diseases among this group: 41 (82\%) fulfilled DSM-III-R criteria for depressive disorders, $22(44 \%)$ for somatoform disorders and 20 (40\%) for anxiety disorders. Over $40(80 \%)$ of them also had infectious and parasitic diseases. None of the people with llaqui was considered healthy in Western medical or psychiatric terms. Participants had more than one condition simultaneously, and comorbidity of somatoform disorders and anxiety disorders was present. Interestingly, the Zung scores, reflecting the severity of depression, were consistent with the psychiatric diagnoses.

\section{Discussion}

People with llaqui, a widespread Quichua illness category, when evaluated medically and psychiatrically by a Quichua biomedically trained doctor, were found to have psychiatric disorders and physical diseases. Clearly, our llaqui patients were ill and in need of medical and psychiatric care. It is surprising that the Quichua healers using supernatural and life-events notions seem to identify people who are psychiatrically ill. Since participants were identified and labelled as ill by both the biomedically trained doctor (using biomedical criteria) and the yachactaita, a remarkable overlap is apparent in the diagnostic work of both practitioners. The implications of the apparent connection between the Quichua illness category llaqui and Western psychiatric categories are not discussed in this paper.

Our finding is in line with studies conducted in other cultural settings. Beiser's investigation in Senegal of 32 Serer patients reported to be suffering from 'illness of the spirit' found that what is considered disordered behaviour by the Serer would be considered to be deviant behaviour by him as a psychiatrist. ${ }^{10}$ Westermeyer's study in Laos showed a similar result: Westermeyer concluded,

'Lao villagers, mostly illiterate and living in a society without psychiatrists, are able to recognize psychosis with a high degree of reliability vis-à-vis experienced clinicians. ${ }^{11}$

Additionally, Jones's qualitative study among the Maori in New Zealand found similarities in the overall diagnostic approaches used by healers and Western physicians. ${ }^{12}$

Our exploratory study suggests that Quichua healers could have the skills to identify people with mental disorders. Recent evidence that cultural factors can have a marked influence on the detection and rating of affective symptoms suggests that diagnosticians from the same cultural background as the patient, such as the Quichua healers, may be more effective detectors of illness than those from different cultural backgrounds. ${ }^{13}$ Although definite conclusions on yachactaitas' diagnostic abilities cannot be drawn safely owing to methodological limitations, it remains an intriguing observation and makes it more difficult simply to dismiss the concept. It would be desirable to conduct carefully designed controlled studies aimed at elucidating the diagnostic reliability of healers, as well as knowing ethnographic details of the emic criteria used by healers for labelling and identifying clinical cases.

The yachactaitas' diagnostic abilities could be useful in the screening of cases in psychiatric epidemiological and public health research and surveys. This finding highlights the contribution of yachactaitas in the provision of mental healthcare for Quichua people living in the Andes, for whom government-funded psychiatric services are non-existent. ${ }^{14}$

Mario Incayawar, MD, MSC, DESS, Runajambi Institute for the Study of Quichua Culture and Health, Otavalo, Ecuador

Correspondence: Dr Mario Incayawar, Director, Runajambi Institute for the Study of Quichua Culture and Health, Otavalo, Ecuador. E-mail: inca@runajambi.org

First received 2 Nov 2007, final revision 14 Jan 2008, accepted 22 Jan 2008

\section{Acknowledgements}

This study was supported by a John Simon Guggenheim Foundation Fellowship in 2006 and in part by Fonds FCAR No. 892027-1, Quebec, Canada. The author thanks Heather Gillespie from Pitzer College and Sioui Maldonado Bouchard for their assistance in reviewing the quality of the English language.

\section{References}

1 Bogoras W. The Chukchee. American Museum of Natural History, 1907.

2 Kleinman A. Patients and Healers in the Context of Culture: An Exploration of the Borderland Between Anthropology, Medicine, and Psychiatry. University of California Press, 1980

3 Manson SM. Physicians and American Indian healers: issues and constraints in collaborative health care. In The Healing Arts (ed M Beiser). Harvard University Press, in press.

4 Hewson MG. Traditional healers in southern Africa. Ann Intern Med 1998; 128: $1029-34$

5 Bastien JW. Healers of the Andes: Kallawaya Herbalists and Their Medicinal Plants. University of Utah Press, 1987.

6 Maddox JL. The Medicine Man: A Sociological Study of the Character and Evolution of Shamanism. Macmillan, 1923.

7 Jilek WG. Indian Healing: Shamanic Ceremonialism in the Pacific Northwest Today. Hancock House, 1982

8 American Psychiatric Association. Diagnostic and Statistical Manual of Mental Disorders (3rd edn, revised) (DSM-III-R). APA 1987.

9 Zung WWK. A self-rating depression scale. Arch Gen Psychiatry 1965; 12 63-70.

10 Beiser M, Ravel JL, Collomb C, Egelhoff C. Assessing psychiatric disorder among the Serer of Senegal. J Nerv Ment Dis 1972; 154: 141-51.

11 Westermeyer J, Zimmerman R. Lao folk diagnoses for mental disorder: comparison with psychiatric diagnosis and assessment with psychiatric rating scales. Med Anthropol 1981; 5: 425-43.

12 Jones R. Diagnosis in traditional Maori healing: a contemporary urban clinic. Pac Health Dialog 2000; 7: 17-24.

13 Mackin $P$, Targum SD, Kalali A, Rom D, Young AH. Culture and assessment of manic symptoms. Br J Psychiatry 2006; 189: 379-80.

14 Incayawar M. Indigenous peoples of South America - inequalities in mental health care. In Culture and Mental Health: A Comprehensive Textbook (eds K Bhui \& D Bhugra): 185-90. Hodder Arnold, 2007. 